\title{
Assessment of Reproductive Health Services in Selected Community Clinics
}

\author{
$1^{\text {st }}$ Umme Asma Abshari \\ Technical Support Officer \\ Civil Surgeon office \\ Cox'sbazar, Bangladesh \\ 1u.a.absari@gmail.com
}

\author{
$2^{\text {nd }}$ Sohel Rana \\ Bridge of Community Development Foundation (BCDF) \\ Bangladesh Technical Support Officer, Civil Surgeon office \\ $3^{\text {rd }}$ Cecep Heriana \\ Insitute of Health Sciences Kuningan \\ Kuningan, Indonesia
}

Cox's bazar, Bangladesh

\begin{abstract}
To assess the utilization of reproductive health services. This was a cross-sectional descriptive study conducted with both qualitative and quantitative approach from January to December 2014 by interviewing 100 service receivers and 10 service providers of 10 community clinic of Cox's Bazar sadar upazilla It was observed that community clinics (CCs) used by the $72 \%$ female health seeker where $50 \%$ of them were housewife. About the knowledge of family planning (FP) methods, $72 \%$ know and $28 \%$ do not know about it. Among $28 \%$ who did not received FP methods $7.14 \%$ don't know about the CCs, $42.85 \%$ don't know about the given services and $50 \%$ didn't received the service due to shame. It has been found that, Immunization of 15-49 years female, antenatal and postnatal care was found $100 \% \&$ only one CC had facility of emergency obstetric care. Nutritional and immunization service for children was $100 \%$ and literate person knows about FP methods were $95.4 \%$. The significant relationship was found between educational status and knowledge about FP method, X2 = 50.375; $P$ value- .000 which was $<.05$. Reproductive health services in CCs were found satisfactory. All the CCs were providing antenatal care which was a very promising sign. Maximum respondents had knowledge about the FP methods but maximum women don't use any contraceptive. So this was a big problem for the policy makers who worked to reduce our population.
\end{abstract}

\section{Keywords: assessment, reproductive health, FP methods}

\section{INTRODUCTION}

Health is the fundamental human rights of human being and the government has a constitutional obligation to ensure public health to all citizens. Therefore health, population and nutrition are among the most urgent development issues of the government of Bangladesh [1].

The Government of Bangladesh, in 1996-2001, planned to establish 18,000 community clinics for provision of primary healthcare services to rural people13,500 as independent new clinics and 4,500 in the existing union and upazila-level health facilities. From 1998 to 2003, 10,723 community clinics were constructed, of which 8,000 were made functional. The Government resumed the CC project with the name "Revitalization of Community-based Healthcare Initiatives in Bangladesh" (RCHCIB).2 Target of setting up 13,500 independent Community clinics. On June 2016, 13,136 CCs were on board [2].

Revitalization of Community Health Care in Bangladesh is the most discussed project in the country's health sector in recent times. International quarters have also shown keen interest in this Bangladeshi initiative to deliver healthcare to the doorsteps of the people. United National Secretary General Ban Ki Moon and World Health Organization (WHO) Director General Margaret Chan had inspected work on the community clinics when visiting Bangladesh. WHO is preparing a report called Community Clinic Health Revolution in Bangladesh [3].

Reproductive Health Service is a service that contributes to reproductive health and well-being through preventing and solving reproductive health problems [4].The service provides women's health services; family planning, safe delivery care, Essential Obstetric Care (EOC), referral services, post-natal care and child healthcare[5].

According to the latest estimate by the United Nations (2015), the current maternal mortality is 176 per 100,000 live births; maternal mortality dropped by $68 \%$ against the 2015 target of $75 \%$ (143.5 per 100,000 live births). According to the United Nations estimate Bangladesh's under-5 mortality rate dropped to stunning 38 per 1,000 live births by 2015 from 144 per 1,000 live births in 1990, current infant mortality rate in Bangladesh is 31 per 1,000 live births, and the neonatal mortality rate is 23 per 1,000 live births. Ensuring universal coverage of measles vaccination is $86.6 \%$.[2]

In the present context of Bangladesh Community clinic is the first level one stop service center for Primary Health Care with emphasis on Maternal and Neonatal Health. It is to be mentioned that normal delivery is being conducted in some community clinics through SBA and CSBA (trained FWA/Female HA) particularly where DSF (Demand Side Financing) and MNH program is going on. Normal delivery is also being conducted in some areas where PLAN Bangladesh is working with RCHCIB.[6].

\section{MATERIAL AND METHODS}

This was a cross-sectional descriptive study conducted with both qualitative and quantitative approach by assessing the existing facilities and interviewing 100 service receivers and 10 service providers. Semi structured questionnaire and checklist was used as a tool for collection of data. Questionnaire-based information was collected by face-to-face interview with respondents. Findings of the visit were collected by observation checklist. Data was collected from 9 AM to 4 PM of office day only. Analysis of data done by Microsoft Excel and SPSS version20. The study was conducted from January to December 2014 \& data were collected purposively in selected $10 \mathrm{CCs}$ of Cox's Bazar sadar upazilla. 


\section{RESEARCH RESULT}

\section{A. Socio-demographic status}

It was observed that, main health seekers in CCs were female. About $72 \%$ female and only $28 \%$ male utilize the CCs. As because females were maximum users of CCs $50 \%$ of them were housewife, $6 \%$ were farmer, $19 \%$ were day labor, $2 \%$ were businessmen, $3 \%$ were service holder and $20 \%$ of them other occupation such as student, driver etc. Users who received the services from CCs $98 \%$ of them were Muslim and 2\% of them were Hindu, $65 \%$ of them were literate and $35 \%$ of them were illiterate:

\begin{tabular}{llcc}
\multirow{2}{*}{ TABLE 1. DISTRIBUTION OF SOCIO-DEMOGRAPHIC STATUS OF THE PATIENTS WHO UTILIZES COMMUNITY CLINICS } \\
\hline Variable & Frequency & Percentage \\
\hline Gender & Male & 28 & 28 \\
& Female & 72 & 72 \\
Occupation & House-wife & 50 & 50 \\
& Farmer & 6 & 6 \\
& Day-labor & 19 & 19 \\
& Businessman & 2 & 2 \\
& Service holder & 3 & 3 \\
& (Govt./ private) & & 20 \\
Religion & Others & 20 & 98 \\
& Islam & 98 & 2 \\
Educational status & Hindu & 2 & 65 \\
& Literate & 65 & 35 \\
& Illiterate & 35 &
\end{tabular}

B. Availability, Use and Procurement of Contraceptive Methods

Availability of FP methods was $100 \%$ except implant. About the knowledge of FP methods, $72 \%$ know about the FP methods and $28 \%$ does not know about it.

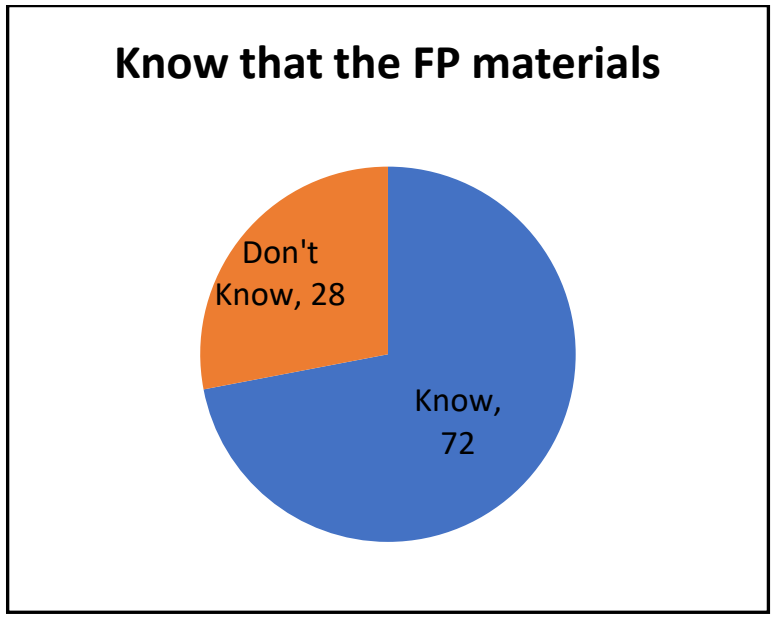

Fig 1. Distribution of knowledge about FP methods

Among 28\% who did not receive FP methods $7.14 \%$ don't know about the CCs, $42.85 \%$ don't know about the given
Item of FP methods were - pill, condom and injection. $72 \%$ women who know about the FP methods they collect single item $44 \%$, two item $10 \%$, multiple item $0 \%$ and no item $46 \%$.

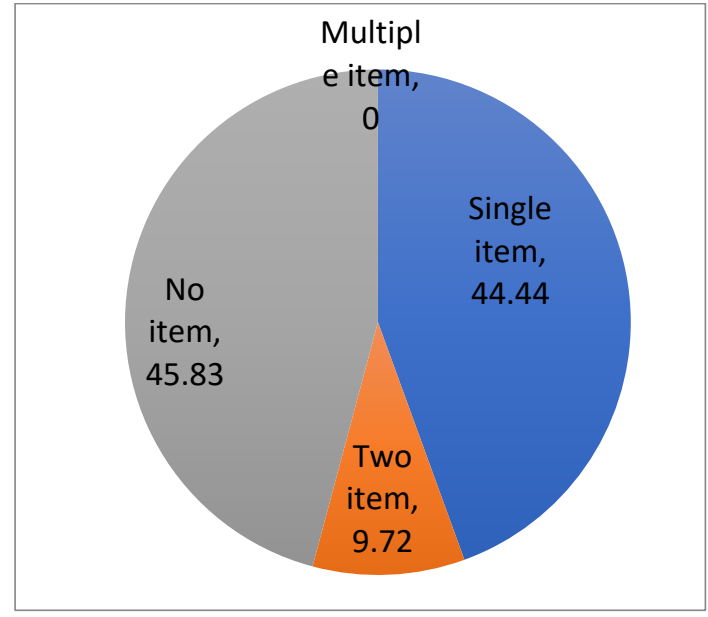

Fig 2. Distribution of FP methods receive from CCs

services and $50 \%$ didn't received the service due to shame. 
TABLE 2. DISTRIBUTION OF RESPONDENTS BY THEIR OPINION ABOUT NOT RECEIVING FP METHOD

\begin{tabular}{llcc}
\hline \multicolumn{2}{c}{ Characteristics } & Frequency & Percentage \\
\hline $\begin{array}{l}\text { If no then, } \\
\text { why? }\end{array}$ & $\begin{array}{l}\text { Don't know } \\
\text { about CC }\end{array}$ & 2 & 7.14 \\
& $\begin{array}{l}\text { Don't know } \\
\text { about given } \\
\text { service } \\
\text { Shame }\end{array}$ & 12 & 42.85 \\
& 14 & 50 \\
\hline
\end{tabular}

Among 72\% women who know about the FP methods they collect those FP material from different places such asGovt. heath centre, CCs, NGOs, pharmacy and others. $58.33 \%$ women collect those FP materials from single centre. $6.94 \%$ choose two centers and $34.72 \%$ does not choose any centre. $0 \%$ women choose multiple centers.

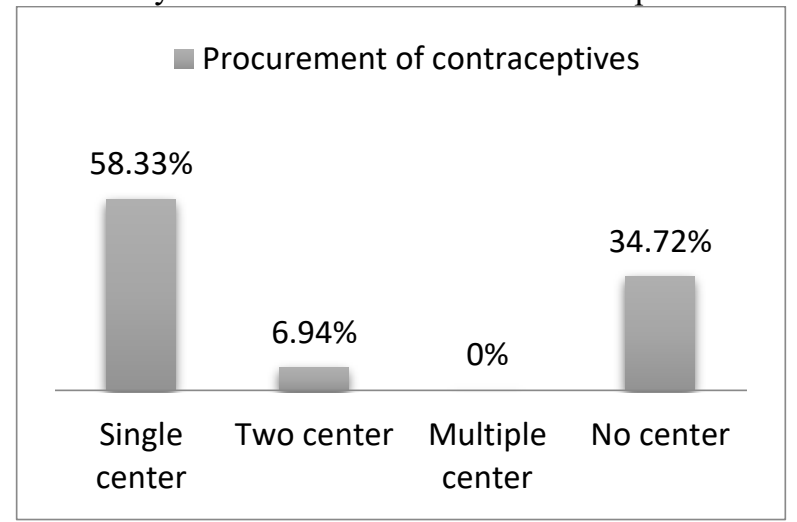

Fig 3. Distribution of procurement of contraceptives

\section{Health Care}

Service provider report that, Immunization for female 1549 years, Iron and folic acid supplementation to pregnant women were found $100 \%$. All the CCs were successfully doing proper antenatal and postnatal check-up. The service providers reported that they had referral systems and referred patients to the upper facilities using printed referral card was $100 \%$.

Only 1 CC provided emergency obstetric care as because they had delivery facilities.

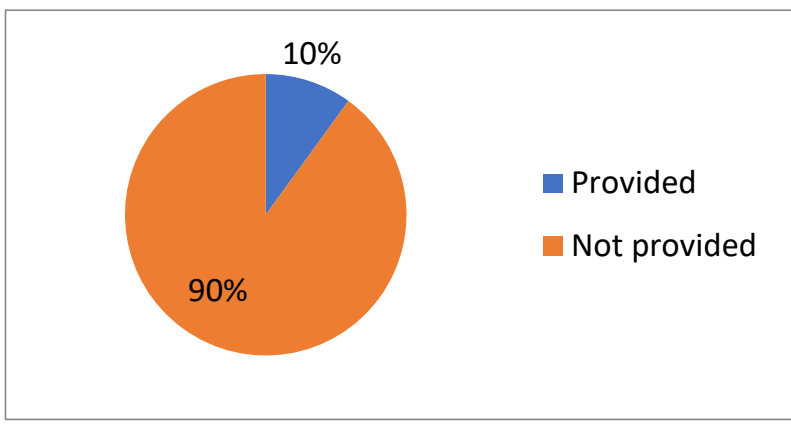

Fig 4. Distribution of emergency obstetric care

\section{Child Healthcare}

When a child came over a $\mathrm{CC}$ the $\mathrm{CHCP}$ asked for registration card and EPI schedule card, nutritional and immunization status check by CHCP were $100 \%$.

It was observed that, weight machine for child \& Height measuring tape was $100 \%$ functioning. Measuring tap $60 \%$ functioning and $40 \%$ were not available. Naso-gastric tubes (small), Baby mucous sucker glass and umbo bag were $90 \%$ not available but available 1 umbo bag was nonfunctioning. Mug for measuring saline (marked) were functioning in $90 \% \mathrm{CCs}$

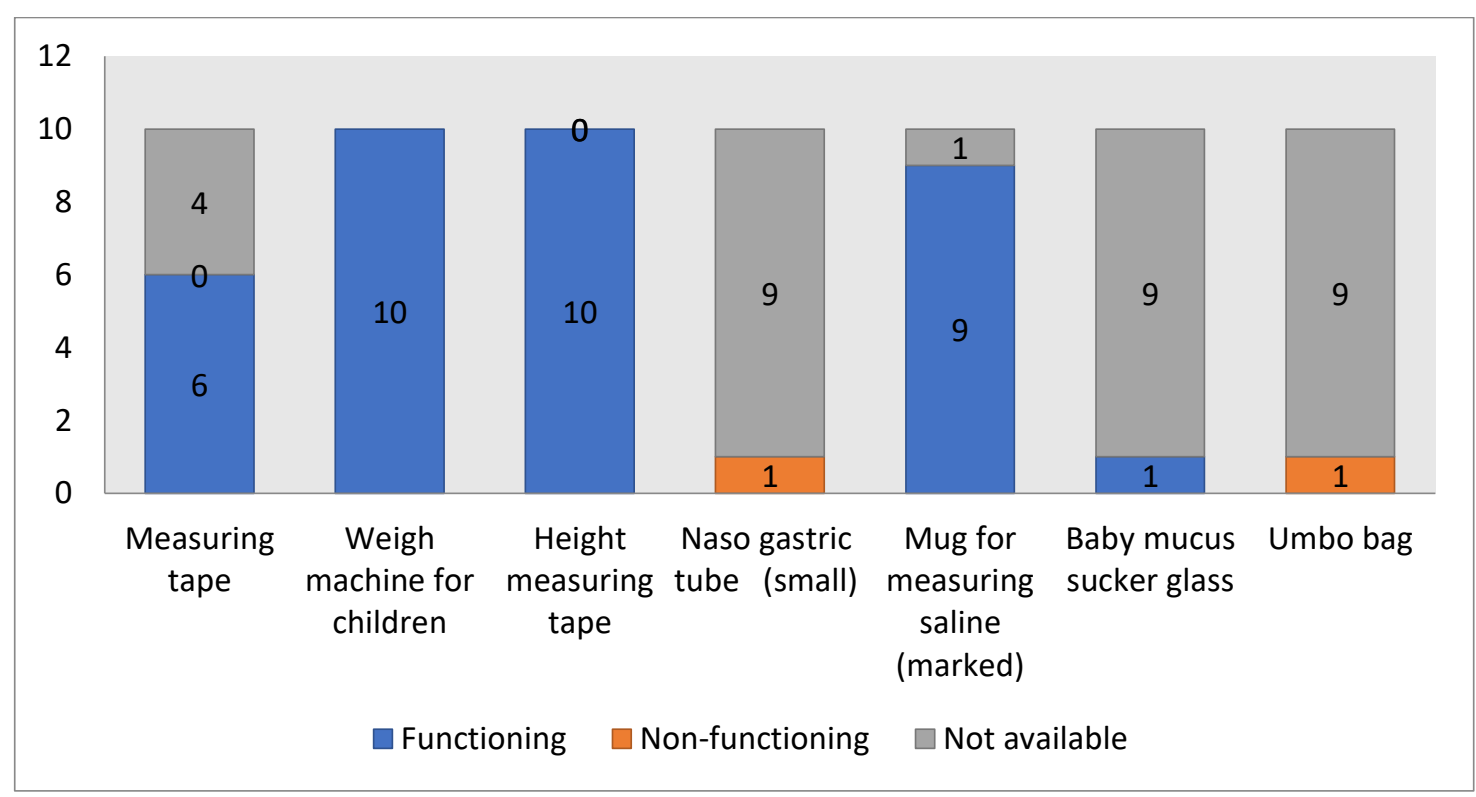

Fig 5. Distribution of status of the instrument 


\section{E. Association between educational status and know about FP method}

It has been found that literate person knows about FP methods were $95.4 \%$ where illiterate persons were $28.6 \%$. The significant relationship was found between educational status and knowledge about family planning, $\mathbf{X}^{2}=50.375$; $P$ value- .000 which was $<.05$

TABLE 3. RELATION BETWEEN EDUCATIONAL STATUS AND

KNOW ABOUT FP METHOD

\begin{tabular}{|l|l|l|l|l|l|l|l|l|}
\hline \multirow{2}{*}{$\begin{array}{l}\text { Educatio } \\
\text { nal status }\end{array}$} & \multicolumn{3}{|l|}{ Know about FP method } & \multicolumn{2}{l|}{ Total } & \multirow{2}{*}{$\mathrm{X}^{2}$} & $\begin{array}{l}\text { P- } \\
\text { value }\end{array}$ \\
\cline { 2 - 8 } & \multicolumn{2}{|l|}{ Yes } & \multicolumn{2}{|l|}{ No } & \multicolumn{2}{|l|}{} & & \\
\cline { 2 - 8 } & $\mathrm{N}$ & $\%$ & $\mathrm{~N}$ & $\%$ & $\mathrm{~N}$ & $\%$ & & \\
\hline Illiterate & 10 & 28.6 & 25 & 71.4 & 35 & 100 & 50.3 & .000 \\
& & & & & & & 75 & \\
\hline Literate & 62 & 95.4 & 3 & 4.6 & 65 & 100 & & \\
\hline
\end{tabular}

\section{DISCUSSION}

It was observed that CCs maximum used by the female person and $50 \%$ of them were housewife. A similar study found that female patients were the most prominent group of health care seekers in CCs.[7]

Users who received the services from CCs, $65 \%$ of them were literate and $35 \%$ of them were illiterate. Here the literate person means that who can give his/her sign and can read a paper not that how many educational level he/she completed. In comparison with NIPORT's study, among the users, overall, $40 \%$ had no education at all and only 9 percent had completed secondary level school, which indicates that people with less education intend to attend the CCs more for health care services than the better educated ones.[8]

Availability of FP methods were $100 \%$ except implant but such methods were not available in most of the CCs registers; rather it was kept by the FWA registers along with the home delivery. So, it was not possible for the FWA to give how many, of a particular method, were supplied in the CCs and how many in the home visits. NIPORT study found that CCs do not get any supply of FP methods such as pill and condoms except the supply of family welfare assistant (FWA).[7]

About the knowledge of FP methods, $72 \%$ know about the FP methods and $28 \%$ does not know about it. Open Access Journal of Contraception 2012 found that almost all married women in Bangladesh (99.9\%) have heard of at least one FP method.8 Among 28\% who did not receive FP methods $7.14 \%$ don't know about the CCs, $42.85 \%$ don't know about the given services and 50\% didn't received the service due to shame. In a journal of Dhaka Medical College 2010 showed that, $11.84 \%$ women were not using contraceptive due to religious prohibition [9]

Among $72 \%$ women who know about the FP methods $58.33 \%$ women collect those FP materials from single centre. According to observation maximum women collect FP materials from single centre as because it was near to their house. $6.94 \%$ choose two centers and $34.72 \%$ does not choose any centre. These women were those who know about the FP methods but don't collect any item because of religious value, fear of never had a baby and fare of side effect and shame. SHOPS project in 2011 found that, private sector sources account for nearly $44 \%$ of modern family planning methods used, with $40 \%$ representing pharmacies where only oral contraceptives and condoms were available. These pharmacies were often a person's first point of contact with the health system, yet play virtually no role in the provision of long acting/ permanent methods.[10]

Service provider report that, all the conducting CCs provide before pregnancy health education.

Service provider report that, Immunization for female 15-49 years, Iron and folic acid supplementation to pregnant women were found $100 \%$. All the CCs were successfully doing antenatal and postnatal check-up. As because it was a root level service delivery for antenatal check-up service provider did registration, took height, weight, measure blood pressure and asked about whether they boil their urine at home or not to find out proteinuria but blood test was not possible to do in those clinics. For post-natal check-up they took weight, measure blood pressure, told about FP methods \& if any complication arises then referred to higher center. The service providers reported that they had referral systems and referred patients to the upper facilities using printed referral card was $100 \%$. A study of NIPORT 2013 says, only antenatal and postnatal cares were provided from the clinics as maternal health care.[8]

$\mathrm{CC}$ which provided delivery services have emergency obstetric care facilities. Only one CC had this facility.

When a child came in a CC the CHCP asked for registration card and EPI schedule card, nutritional and immunization status check by $\mathrm{CHCP}$ are $100 \%$. CHCP check malnutrition by measuring mid arm circumference and asking the dietary habit. $\mathrm{CHCP}$ check anaemia by retracting the lower eyelid.

It was observed that literate person had more knowledge about FP method than illiterate person. This observed difference may be due to literate person get more information by reading newspaper, leaflet and bill board about family planning method. Suggest that efforts towards reducing national maternal mortality in Bangladesh could be aided by investments into education, poverty reduction and the strengthening of reproductive healthcare services through community clinics, with particular focus on rural areas[11]

\section{CONCLUSIONS AND SUGGESTIONS}

Reproductive health services in CCs were found satisfactory. In CCs most prominent group of health care seekers were female. As because female was the maximum in count most of them were housewife. Maximum respondents had knowledge about the FP methods but maximum women don't use any contraceptive. So this was a big problem for the policymakers who worked to reduce our population. Antenatal care was given properly with Iron $\&$ Folic acid supplementation. It was observed that literate person had more knowledge of FP method than illiterate person which was about $95.4 \%$. 


\section{ACKNOWLEDGMENTS}

I did this research during the thesis part of my $\mathrm{MPH}$ degree. I would like to take this opportunity to express my acknowledgement to several persons and institution whose support immensely contribute to make the study success. First and foremost, I wish to convey my heartfelt gratitude to my supervisor, Assistant Professor Dr. Khorshed Ali Miah, for his tremendous help and encouragement with my thesis. I am highly indebted to him for his invaluable advice and intellectual guidance throughout my thesis writing. Without his support my thesis would not be able to see the light.

I would like to pay cordial thank to Professor and Head of Department of Public health and Hospital Adminstration, NIPSOM Dr. Baizid Khoorshid Riaz for his kind approval and overall suggestions during the study.

I am also grateful to Honorable Director NIPSOM, Professor Dr. Akhtarun Naher for her sincere cooperation in all my academic affairs. I would like to convey cordial thanks to Assistant Professor Dr. Zahidur Rahman, Professor Dr. Md. Ziaul Islam, Assistant Professor Dr. Mazharul Islam to enrich me with their profound advice, which helped me to refine and accomplish the daunting task.

\section{REFERENCES}

[1] Ministry of Health and Family Welfare Government of People's Republic of Bangladesh, "Health, Population and Nutrition Sector Development Program," 2012.

[2] D. G. H. S. DGHS, "Health bulletin," DGHS, hal. 18, 21, 29-31, 36-37, 2014.

[3] S. Moral dan K. Roy, "People's confidence in community clinics increases," Photom Alo, Bangladesh, 2014.

[4] D. R. Tobergte dan S. Curtis, Program of Action_Adopted at the International Conference on Population and Development, Cairo 1994, vol. 53, no. 9. 2013.

[5] A. Al-Sabir, S. N. Mitra, S. Islam, S. K. Bhadra, A. Cross, dan S. Kumar, "Bangladesh Demographic and Health Survey (BDHS)," Natl. Inst. Popul. Res. Training, Mitra Assoc. ORC Macro, 2004.

[6] "Http://www.communityclinic.gov.bd/about.php." [Daring]. Tersedia pada: http://www.communityclinic.gov.bd/about.php.

[7] M. H. Millat, M. U. Jahan, M. Hasan, K. Alam, M. M. Hossain, dan M. S. Miah, "Status and prospect of Community Clinic in rural areas of Bangladesh: An overview of health workers," Bangladesh Med. Res. Counc. Bull., vol. 37, no. 2, hal. 76-77, 2011.

[8] P. in S. S. M. R. T. \& D. (PSSMRTD), "Utilization of Community Clinic, National Institute of Population Research \& Training (NIPORT)," 2013.

[9] S. K. Ferdousi et al., "Unmet need of family Planning among rural women in Bangladesh," J. Dhaka Med. Coll., vol. 19, no. 1, hal. 11-15, 2010.

[10] S. Umapathy, "Bangladesh family planning private health sector assessment. Brief.," 2013.

[11] S. Yaya, G. Bishwajit, dan M. Ekholuenetale, "Factors associated with the utilization of institutional delivery services in Bangladesh,” PLoS One, vol. 12, no. 2, hal. e0171573, 2017. 